\title{
SLIDING DROOP CONTROL FOR DISTRIBUTED GENERATION IN MICROGRIDS
}

\author{
${ }^{1}$ Bruno W. França, ${ }^{2}$ Emanuel L. van Emmerik, ${ }^{2}$ Juliano F. Caldeira, ${ }^{2}$ Mauricio Aredes \\ ${ }^{1}$ Department of Electrical Engineering, Fluminense Federal University, Niterói - RJ, Brazil \\ ${ }^{2}$ Department of Electrical Engineering, Federal University of Rio de Janeiro, Rio de Janeiro - RJ, Brazil \\ e-mail: bwfranca@id.uff.br, emmerik@lemt.ufrj.br, julianoc@lemt.ufrj.br, aredes@lemt.ufrj.br
}

\begin{abstract}
This paper proposes a fully autonomous controller that slides the droop curves of a Static Synchronous Generator, avoiding the need of hierarchical controllers to perform power sharing and frequency and voltage regulation. The aim of this controller is to enhance the primary controller in order to perform additional functionalities in a similar way as those performed in a secondary control level hierarchy, avoiding the need of a communication-system and without mischaracterizing the primary behavior as a virtual synchronous machine. The proposed seamless controller is still compatible with conventional communication-systems, and can receive inputs from hierarchical controllers. In grid-connected microgrids, distributed generation (DG) units perform active-power supply and adequate voltage regulation, whereas the system frequency is imposed by the grid. Contrarily, in islanded microgrids, DG units have to perform activepower sharing between all units, reactive-power sharing, as well as to ensure adequate frequency control and voltage regulation. When static droop curves are employed, power dispatch planning along with coordinated set of DG units is required to achieve accurate active-power sharing. This drawback is mitigated with the proposed fully autonomous controller. Simulation results were obtained in a microgrid scenario to demonstrate the effective approach for power sharing. Experimental results are also presented.
\end{abstract}

Keywords - Distributed Generation, Droop Control,
Microgrid, Static Synchronous Generator,
Synchronverter.

\section{INTRODUCTION}

In modern power systems, the exponential increase of renewable energy generation connections and other types of distributed generation (DG) is changing the conventional Centralized Power System (CPS) arrangement. Therefore, the Distributed Power System (DPS) configuration is arising, and it is characterized by many generators spread into the grid, in which each one generates a small rate of the total power demanded by the loads [1]-[3]. The DPS configuration also leads to the upgrowth of microgrids. The operative modes in which a microgrid is working with regards to the

Manuscript received 09/04/2017; first revision 02/06/2017; accepted for publication 26/07/2017, by recommendation of Editor Marcelo Cabral Cavalcanti. power grid are usually separated in two possible conditions: the grid-connected mode and the islanded mode.

The energy generated by renewables is usually injected into the grid through Voltage Source Converters (VSC). There are some restrictions to increasing the number of VSCbased distributed generators and difficulties to harmonize the operation of multiple parallel-connected VSCs, e.g. undesired circulating currents in between DG units, harmonic currents propagation, and the need of communication systems to perform power sharing between DGs [1].

A well-known control method for parallel-connected converters is the emulation of Virtual Synchronous Generators (VSG). The behavior of the power converters controlled by this method is naturally stable and they can be connected in parallel with actual rotational machines like those employed in hydropower plants. In fact, the goal is to emulate an ideal synchronous generator with adaptive parameters to achieve enhanced performance [4]-[8]. The concepts of controlling a VSC as a virtual synchronous generator are generally known as Static Synchronous Generator (SSG) [5], synchronverter or cyber synchronous machines (CSM) [9].

The SSG controller uses frequency and voltage droop curves to perform power sharing [10]. In islanded microgrids, the power sharing, and frequency- and voltageregulation play a primordial role to ensure system stability [11], [12]. The control of both active-power sharing and frequency regulation are impossible to be achieved simultaneously by using only static droop control methods. The same occurs for the reactive-power sharing and the voltage regulation. A hierarchical control architecture is necessary to perform such functionalities and to coordinate DG units in real-time. In summary, a hierarchical control structure is composed of the primary, secondary and tertiary control levels. The primary control is local and responsible for ensuring power sharing and short-term power equilibrium between DG units and loads. The secondary control aims to coordinate DG units in order to restore the system frequency and provide voltage regulation. Moreover, when operating the microgrid in islanded mode, a slower synchronizing scheme adjusts the frequency and phase angle at the point of coupling with the power grid, such that it keeps ready to reclose with the grid. The hierarchical control structure is designed considering a certain dependency of data communication system between units (decentralized control) or between units and a centralized microgrid controller. The higher tertiary control level concerns about economic and energetic aspects to determine a day-ahead program for the power dispatch in the microgrid. 
Some hierarchical controllers have shown efficient performance with a low-bandwidth communication link [13]. In a different way, i.e. without the use of a communication link, this paper aims to move "the secondary control functions" into the primary control of each DG unit. This aim follows recent trends of autonomous grid-components such as presented in [9]. In this respect, communication systems would play an important role in the management of energy resources and consumption, but cannot be an obstacle in terms of ensuring the system reliability. The autonomous pattern of DG units may then provide suitable operational conditions, even in the absence or break down of communication, with adequate frequency control and voltage regulation performed by the primary controller.

Dynamic droop controls were already proposed in recent researches as in [14]-[16]. In [14] the droop control method is used as a solution to avoid critical communication among Uninterruptable Power System (UPS) units, which are controlled as voltage sources in both islanded and gridconnected modes. The droop coefficient is controlled as a function of the State-of-Charge (SoC) of batteries, and thus the overall active power flow is according to the power demand and availability. However, it still needs a low bandwidth communication system to report the microgrid operation mode and receive the active and reactive set points.

The autonomous pattern of DG units with the proposed controller provides suitable conditions of operating continuously as a SSG without changes in the controller, even during transitions between islanded and grid-connected mode. The novelty here is to simultaneously realize active/reactive power sharing and frequency/voltage regulation without the need of any communication channel between DG units. The sliding characteristic ensures a continuous variation, with fixed speed, of the droop curves. As a result, negligible frequency/voltage deviation and power sharing are achieved with local voltage and current measurements only, thus diminishing the demand for a communication channel. It is important to highlight that the proposed controller can be employed with all seamless droop-controlled VSGs presented in the current literature.

In summary, the DG unit connected in a microgrid should achieve the following goals:

In islanded mode of operation

- Perform suitable frequency control and voltage regulation within a predictable margin of error;

- Share the active power between all DG units proportionally to their set points;

- Share the reactive power between DG units connected at the same bus or connected at buses that are interconnected by negligible line impedances.

In grid-connected mode of operation

- Inject active power according to its set points;

- Inject reactive power according to the voltage set point to perform voltage regulation along the microgrid.

Active power set points are considered to come from a local maximum power point tracking (MPPT) in the primary source (renewable energy generation system), though, can be dictated by a tertiary control in case of an existing communication channel and energy management system. In case of absence of a communication system, expected to occur especially for smaller DGs [9], the voltage profile along the microgrid and the system frequency have to be kept at acceptable values, even during islanded mode of operation. This paper revises the fact that when the original controller of the SSG and fixed droop curves are applied, the power sharing depends on the slope of the droop curve and active power set point. This is a drawback in case of power sharing between units in a system with predominance of intermittent power generation and without communication system, which is a reasonable configuration in microgrids with large amount of small and medium-sized generators in which the cost of implementing a communication system is unreasonable or not cost-effective. The new sliding droop control method overcomes these issues. The pattern of sliding is preestablished in such manner that only the measurement of local variables is required. The knowledge of the gridimpedance is not necessary and there is no need of islanding detection since the controller is the same for both situations, i.e. during grid-connected or islanded modes of operation.

This paper is organized in seven sections. After this introduction, Section II summarizes the classic SSG controller and discusses some drawbacks of employing the classic droop control method without a communication system in islanded and grid-connected modes. Section III presents the sliding droop control and its implementation in the SSG controller. Section IV provides stability analysis, section $\mathrm{V}$ the simulation analysis and section VI the experimental results. The final section presents the conclusions.

\section{REVISION OF THE DROOP METHOD}

\section{A. Droop Method and the SSG Performance}

The classic droop concept will be analyzed through the active-power droop curve in Figure 1. In this figure, $\omega_{0}$ is the no-load frequency, $\omega_{\text {ref }}$ is the frequency reference, $\alpha$ is the slope of the droop curve and $P_{n o m}$ is the nominal activepower value of a generator. The classic droop method is a well-known solution widely applied in CPS [17], [18]. In this scenario the system frequency is mainly imposed by bigger power generators that are in operation and each generator has predictable power availability. Moreover, the system counts with communication systems to establish hierarchical controllers. This leads to a situation where the power availability of the generator is realized as the nominal power $P_{\text {nom }}$, and the droop curve is easily adjusted through the tertiary hierarchical controller, with the set of $D_{p}$ and $P_{n o m}$ according to economical aspects and dispatch planning. Analyzing the droop curve of Figure 1 in per unit with $P_{\text {nom }}$ defined as $1 \mathrm{pu}$, proportional power sharing is achieved by applying the same $D_{P}$ constant to the generators [19]. Hence,

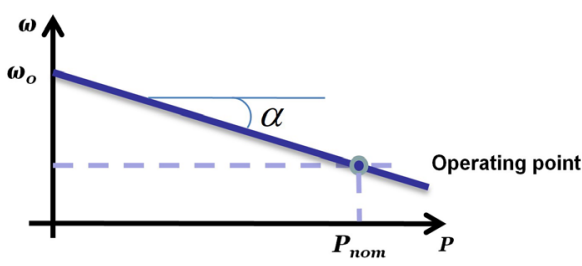

Fig. 1. Classic droop method. 
$D_{p}$ can established as

$$
D_{p}=\frac{P_{\text {nom }}}{\Delta \omega_{\max }}=\cot (\alpha)
$$

where $\Delta \omega_{\max }$ is the maximum allowed frequency deviation. Despite the negative slope, $D_{p}$ is defined here as it is used in primary controllers, i.e. as a positive constant [5]. The secondary hierarchical controller slides the droop curves of all generators to ensure that the operating point is positioned at the grid frequency reference. Hence, Figure 1 represents the steady-state of the droop curves of every generator in a CPS, which results in proportional power sharing and regulated frequency. Though, in a normal situation, the generated power is less than $P_{n o m}$, resulting in a downward movement of $\omega_{0}$ by the secondary controller to maintain the dispatched power at $\omega_{\text {ref }}$.

The application of the droop method in a DPS will be analyzed through the generalized schematic of a DG unit depicted in Figure 2 and the example depicted in Figure 3, which presents the active-droop curve of two DG units connected in a microgrid, with two different operating point situations.

In Figure 2 the SSG controller receives the terminal voltage $\left(v_{a, b, c}\right)$ and the current $\left(i_{a, b, c}\right)$ of the DG unit power circuit, along with the control inputs from the Energy Generator System $\left(P_{\text {set }}\right)$.The outputs are the Pulse Width Modulated (PWM) gate pulses $\left(\mathrm{G}_{1 \text { to } 6}\right)$ for the drivers of the power converter (VSC). An LCL-filter is considered here to filter the switching frequency harmonics of the VSC. A common circuit breaker can be used to connect the DG unit with the microgrid before startup procedures. The dc-link is composed of a capacitor bank with a voltage $V_{d c}$ that is

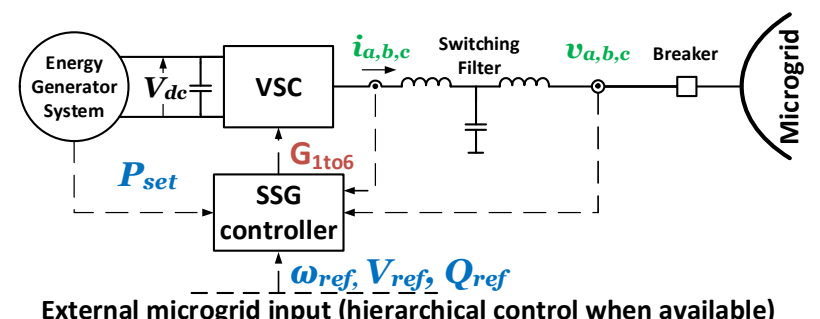

External microgrid input (hierarchical control when available)

Fig. 2. Generalized control of a DG unit with SSG controller.

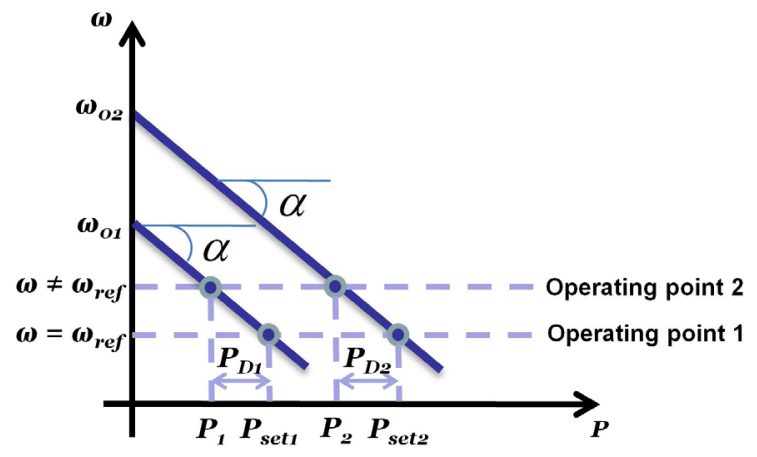

Fig. 3. Example of droop curves (in pu) and operation point analysis. controlled by the Energy Generator System. It is assumed that this Energy Generator System is provided with an energy management system. Besides, it is responsible to inject energy into the dc link and to keep the dc voltage around its reference value, according to the power being injected by the DG unit into the microgrid. The energy management system also provides the power order, $P_{\text {set }}$, to the Digital Signal Processor (DSP), which gives the information about the maximum, or the desired, or even the ongoing available power generation. In other words, the active power set point $P_{\text {set }}$ can be understood as a "maximum/desired" power that the DG unit should deliver to the microgrid or to the grid.

In this work, DG units are considered to provide reactive power only due to voltage deviation at the point of connection. In this sense, the reactive-power reference is omitted since it is always considered to be zero. Moreover, several topologies of SSG controller may be used in the control structure of Figure 2, such as those presented in [4], [20]-[22]. For instance, Figure 4 depicts a SSG control structure based on [4] where the input and output variables $\left(\mathrm{P}_{\text {set }}, \omega_{\text {ref }}, \mathrm{V}_{\text {ref }}, \mathrm{Q}_{\mathrm{ref}}, \mathrm{v}_{\mathrm{a}, \mathrm{b}, \mathrm{c}}, \mathrm{i}_{\mathrm{a}, \mathrm{b}, \mathrm{c}}\right.$ and $\left.\mathrm{G}_{1 \text { to } 6}\right)$ are highlighted.

Figure 3 will be analyzed in steady-state condition. The indexes $i=1,2$ identify the parameters of each SSG; $\omega_{0}$ is the no-load frequency; $\omega$ is the inner (calculated) frequency of all SSG, which is the same as the grid frequency in steadystate condition; $D_{p}$ is the droop gain; $P$ is the instantaneous active power delivered by the DG unit; and $P_{D}$ is the activepower deviation due to the droop effect. Hereafter, the index $i$ will be omitted whenever the analysis is generically applied to a single DG unit. In a comparison between Figure 1 and Figure 3, the difference of the employment of $P_{\text {set }}$ instead of $P_{n o m}$ is clear in the DPS scenario. This change of nomenclature is suitable due to the intermittent power availability of renewables in DPS. Then, $P_{n o m}$ is realized as the installed capacity of the generator in order to determine $D_{p}$ constant as (1).

When the microgrid is operating in grid-connected mode,

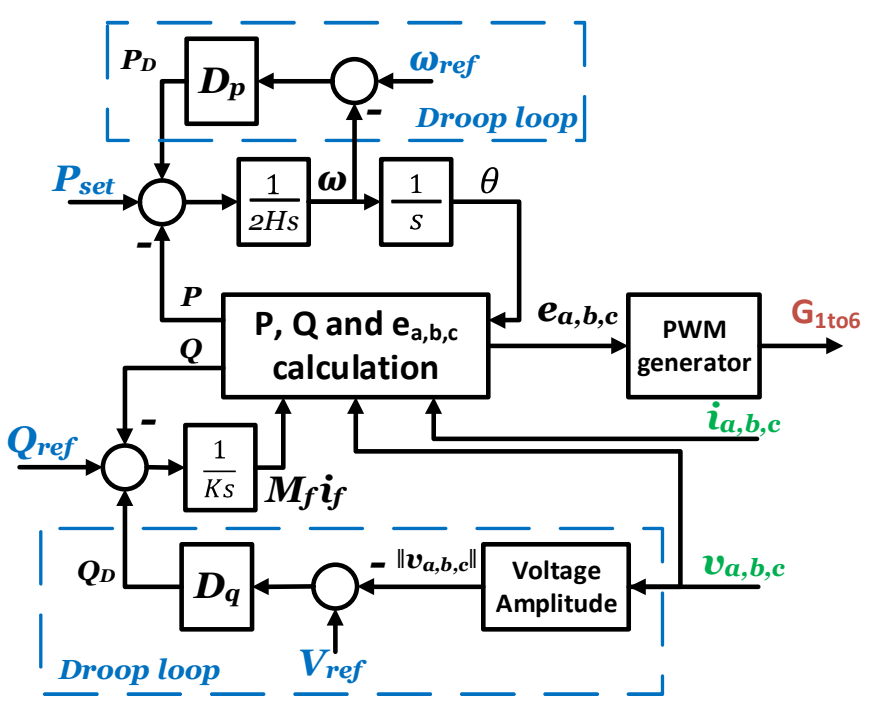

Fig. 4. Example of SSG controller. 
the frequency regulation $\left(\omega=\omega_{\text {ref }}\right)$ is ensured by bigger power generators, thus the power dispatch of all DG units are equal to $P_{\text {set }}\left(P=P_{\text {set }}\right)$, and $P_{D}$ is zero. This is the situation found in operating point 1 . Therefore, the variability of $P_{\text {set }}$ is irrelevant for the active-power sharing.

On the other hand, in islanded microgrids the frequency differs from the reference whenever the load demand is not equal to the available power. If the system counts with a communication system and hierarchical controllers, the droop curves of the DG units can be constantly adjusted and power sharing and frequency regulation are ensured, However, this is not the case in a DPS with no communication system and with intermittent renewable generations that continuously vary their available power reference values, $P_{\text {seti }}$. This situation is exemplified in operating point 2 . In order to ensure that each DG unit will dispatch power proportionally to its currently available resource, the ratio between $P$ and $P_{\text {set }}$ have to be the same for each unit. Thus, extending to an islanded microgrid with $n$ DG units the following equation has to be satisfied:

$$
\frac{P_{1}}{P_{\text {set } 1}}=\frac{P_{2}}{P_{\text {set } 2}}=\cdots=\frac{P_{n}}{P_{\text {setn }}} .
$$

In a classic SSG controller [5], considering the design of the controller in per unit, with $\omega$ approximately $1 \mathrm{pu}$, and with one pair of poles, the electromechanical equation can be stated as

$$
P_{\text {set }}-P+D_{p}\left(\omega_{\text {ref }}-\omega\right)=2 H \frac{d \omega}{d t}
$$

where $H$ is the virtual inertia. In steady state, no virtual kinetic energy is being exchanged between the electrical or mechanical system and the virtual rotor mass, that is, $H \frac{d \omega}{d t}=0$. Then, according to (3):

$$
\begin{aligned}
P_{\text {set } 1}-P_{1}= & P_{\text {set } 2}-P_{2}=\cdots=P_{\text {setn }}-P_{n}= \\
& -D_{p}\left(\omega_{\text {ref }}-\omega\right) .
\end{aligned}
$$

Equation (4) means that the difference between the dispatched active-power and the available power of each DG unit is the same, which is not the same as the proportionality of power sharing achieved in (2). In other words, this situation leads to an equal droop value, $P_{D}$ (compare $P_{D 1}$ and $P_{D 2}$ in Figure 3), independently of the available power of each DG unit, $P_{\text {set }}$. Therefore, the classic SSG controller with the classic droop method is not able to achieve proportional power sharing according to the available power of each DG unit. In actual microgrids, different values of $D_{p}$ may be employed as a mean of weighing the power sharing between generators, as usually performed in CPS. In this case, the power sharing in the islanded microgrid is not stated by (2) either.

\section{B. Droop Method and the Area Electric Power System (EPS) Operation}

Another drawback of the conventional droop method is related to the magnitude of the frequency deviation. A solution to achieve reduced frequency deviation in an islanded microgrid might be accomplished by decreasing $\Delta \omega_{\max }$, which corresponds to increase the gains $D_{p_{i}}$. However, this is not a good solution in grid-connected mode and can degenerate the performance of the DG units, as well as cause instability during transitions between isolated and grid-connected microgrid modes of operation [23]. A possible solution for this drawback was presented in [21], where two different droop loops were used for the steadystate and transitory responses. Nevertheless, the frequency measured at the Point of Common Coupling (PCC) was employed as input of the droop loop used for the transitory response, which may introduce the dynamics of the PLL that tracks the PCC frequency into the SSG controller.

The IEEE standard 1547 [24] in the amendment [25] determines that Distributed Resources (DR), which include DG, shall be able to provide modulated power output as a function of frequency according to pre-established and field adjustable ranges of deviation. For instance, this requirement is intended to permit the area EPS operator to count on DR participation to support the grid robustness. In this sense, fixed droop curves would not be suitable to achieve both reduced frequency deviation in islanded mode and modulated power output in grid-connected mode.

\section{PROPOSED SLIDING DROOP CONTROL}

The "sliding droop control" term is adopted here because the new control method will vary continuously the no-load reference values $\omega_{0}$ and $V_{0}$ of the $P \times \omega$ and $Q \times V$ droop curves, as shown in Figure 5. As the proposed control is quite similar for both the active- and reactive-power loops, the analysis will remain focusing on the active-power control loop. The details of the reactive-power control loop will be introduced afterwards.

The control structure depicted in Figure 2 is adapted with the proposed controller in Figure 6. Although a communication system is not required, the proposed controller is still compatible with conventional ones, and can receive inputs from hierarchical control systems if provided. Therefore, in a microgrid without communication system the frequency and voltage references $\omega_{\text {ref }}$ and $V_{\text {ref }}$ are preset values $(1.0 \mathrm{pu})$, while they are input variables in microgrids with communication system and hierarchical control. The droop loops for both active- and reactive power control are removed from the SSG controller when the sliding droop control is employed (see the detached boxes in Figure 4), since it will be responsible for ensuring the droop effect. Moreover, the SSG inner control variables $P, Q, \omega$ and $V$ are sent to the sliding droop control, while the $P_{D}$ output replaces $P_{\text {set }}$ to feed the active-power set point in the SSG controller and $Q_{D}$ is provided as a result of the sliding of the reactivepower droop curve (compare Figure 2 and Figure 6).

The sliding-droop control loops are depicted in Figure 7. 
The control structures are similar for both active- and reactive-power control loops. The start values $\omega_{\text {start }}$ and $V_{\text {start }}$ can be obtained through an auxiliary positive-sequence detector [26], and are useful to avoid higher transients during the startup of the DG unit. If the grid is already powered before the startup, the start values are equal to the grid, i.e. $\omega_{\text {start }}=\omega_{\text {grid }}$ and $V_{\text {start }}=V_{\text {grid }}$. Hence, $\omega_{0}$ and $V_{0}$ are equal to these grid values ( $\delta \omega_{0}$ and $\delta V_{0}$ are initially zero), resulting in practically zero injected powers, $P$ and $Q$. Otherwise, if the grid is not powered, $\omega_{\text {start }}=\omega_{\text {ref }}$ and $V_{\text {start }}=V_{\text {ref }}$.

The main idea of the sliding droop control is to slide the droop curves in order to place them in a position that tracks the frequency and the voltage in a sliding reference that is the sum of the fixed (or hierarchical-control ) references $\left(\omega_{\text {ref }}\right.$ and $\left.V_{\text {ref }}\right)$ and the deviations $\delta \omega_{\text {ref }}$ and $\delta V_{\text {ref }}$. These deviations are determined through functions that achieve power sharing proportional to the set-points with reduced deviation according to the actual active and reactive powers of the DG units and their corresponding set points.

The deviation function for the active-power control is established as

$$
\delta \omega_{\text {ref }}=k_{S \omega}\left(1-\frac{P}{P_{\text {set }}}\right), \text { for } P \leq P_{\text {set }}, \quad \text { and } 0<P_{\text {set }} \leq 1
$$

where $k_{S \omega}$ is the maximum allowed frequency deviation in steady state. It is important to highlight that $k_{S \omega}$ is constant and the same for all DG units.

The sliding-direction control block will determine if the droop curve slides up or down by controlling the input selector according to the following rule:

$$
\begin{gathered}
\text { if } \omega>\omega_{\text {ref }}+\delta \omega_{\text {ref }} \text { or } P>P_{\text {set }} \therefore \text { slide down }(-1) \\
\text { if } \omega<\omega_{\text {ref }}+\delta \omega_{\text {ref }} \therefore \text { slide up } \quad(+1) .
\end{gathered}
$$

Note that this controller does not depend on $D_{P}$ gain. In this way, reduced frequency deviation can be achieved in steady state by using a reduced $k_{S \omega}$ value, while suitable $D_{p}$ value can be used to work properly in grid-connected mode, according to the requirements of the area EPS operator.

In steady state the frequency is the same for all DG units. Therefore, if there is enough available energy to feed the system, the rules in (6) guarantee that

$$
\omega=\omega_{\text {ref }}+\delta \omega_{\text {ref }}
$$

and, consequently, for DG units identified by indexes $1,2, \ldots, n$ :

$$
\delta \omega_{r e f_{1}}=\delta \omega_{r e f_{2}}=\cdots=\delta \omega_{r e f_{n}}
$$

By substituting (5) in (8) and simplifying, it follows that

$$
\frac{P_{1}}{P_{\text {set } 1}}=\frac{P_{2}}{P_{\text {set } 2}}=\cdots=\frac{P_{n}}{P_{\text {set } n}}
$$

which is the sharing condition stated in (2). Hence, the active-power set point does not interfere on the power sharing when the proposed sliding droop controller is adopted. Furthermore, in islanded microgrid the frequency deviation in steady-state is ruled by (5), (8) and (9) and can be calculated as:

$$
\delta \omega_{\text {ref }}=k_{S \omega}\left(1-\frac{P_{\text {load }}}{\sum_{i=1}^{n} P_{\text {seti }}}\right)
$$

where $P_{\text {load }}$ is the total load connected at the microgrid.

For instance, let's suppose a microgrid with two DG units operating in islanded mode, with $P_{\text {set } 1}=1.0 \mathrm{pu}$ and $P_{\text {set } 2}=0.5 \mathrm{pu}$ and the total load equal to $P_{\text {load }}=0.9 \mathrm{pu}$. In this case, the desired power sharing would be $P_{1}=0.6 \mathrm{pu}$

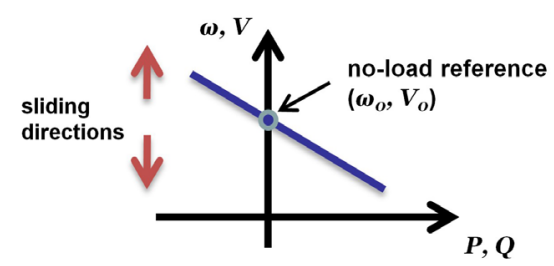

Fig. 5. Sliding droop control method.

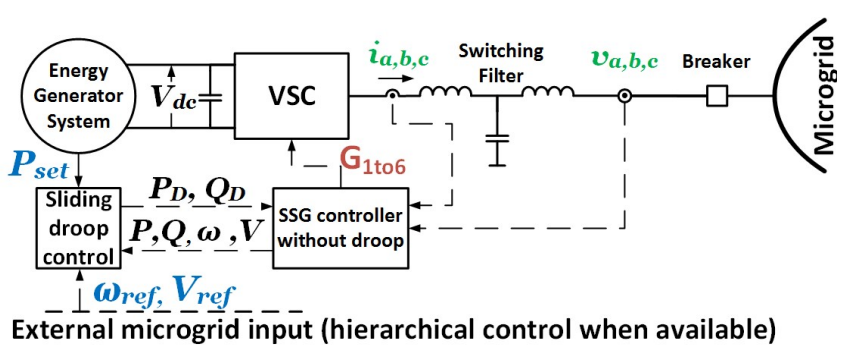

Fig. 6. Generalized control of a DG unit with SSG controller and the proposed sliding droop control.

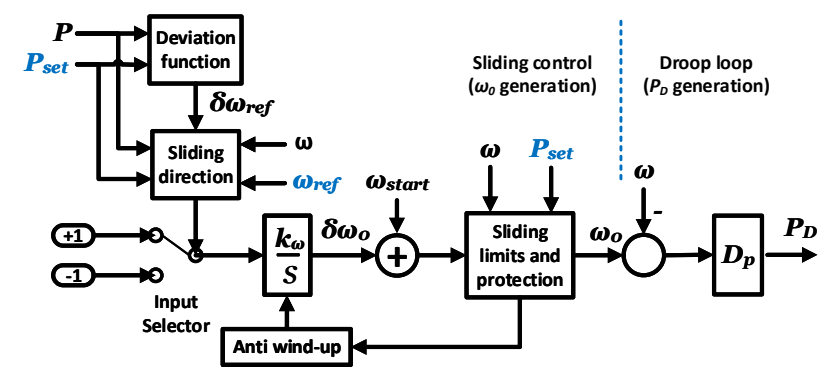

(a)

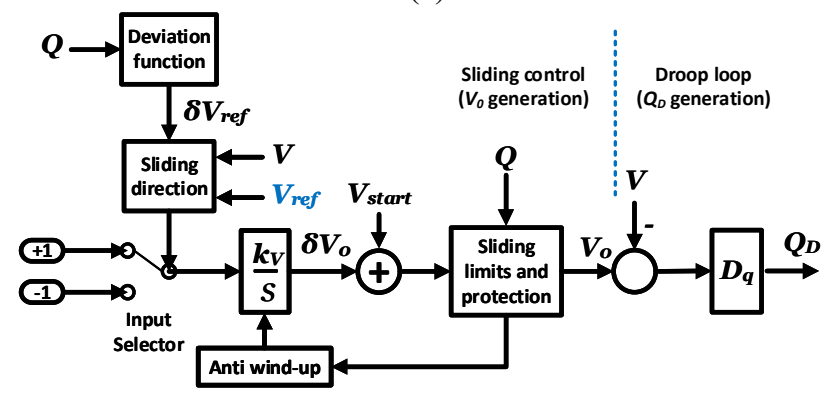

(b)

Fig. 7. Sliding droop control: a) active power, b) reactive power. 
and $P_{2}=0.3 \mathrm{pu}$ according to (9). Table $\mathrm{I}$ and Figure 8 present two different scenarios of sharing in order to analyze the functionality of the proposed controller. In the first scenario the initial sharing condition is considered as $P_{1}=0.7 \mathrm{pu}$ and $P_{2}=0.2 \mathrm{pu}$, which means that $P_{1}$ has to decrease and $P_{2}$ has to increase to satisfy (9). Conversely, in the second scenario $P_{1}=0.5 \mathrm{pu}$ and $P_{2}=0.4 \mathrm{pu}$, then $P_{1}$ has to increase and $P_{2}$ has to decrease. Each scenario evaluates the sliding direction, ruled by (6), for three initial frequency conditions according to the range defined by the frequency deviation of the DG units $\left(\delta \omega_{\text {ref } 1}\right.$ and $\delta \omega_{\text {ref } 2}$ from (5)). These scenarios cover all possibilities in terms of initial condition of active-power dispatch and microgrid frequency, related to $\delta \omega_{\text {ref } 1}$ and $\delta \omega_{\text {ref } 2}$, in normal operational condition, i.e. without overload condition.

The consequences of the sliding actions in the microgrid are highlighted in the last two columns of Table I. Therefore, the microgrid frequency is controlled whenever it is out of the range between the frequency deviations established by the DG units, and no change in the active-power sharing occurs in this situation. This control action is realized in the Px $\omega$ curves realized in Figure 8.a, c, d and f, where both curves are sliding in the same direction. When the microgrid frequency is within the aforementioned range, the droop curves slide in opposite directions, as depicted in the Px $\omega$ curves of Figure 8.b and d. In this case, Table I indicates that the active-power sharing changes in the direction of achieving the desired power sharing. As a result of such active-power change, new values of $\delta \omega_{\text {ref }}$ deviations are obtained, since $\mathrm{P}$ assumes a new value in (5). Note that, in both scenarios, the change of $\delta \omega_{\text {ref } 1}$ and $\delta \omega_{\text {ref } 2}$ causes a tightening in the range between these frequency deviations, which leads both DG units to achieve equal values of $\delta \omega_{\text {ref }}$ in steady-state, as established by (8). Hence, both scenarios present the desired power sharing in steady-state, satisfying (9), with $P_{1}=0.6 \mathrm{pu}, \mathrm{P}_{2}=0.3 \mathrm{pu}$ and final microgrid frequency equal to $\omega_{\text {ref }}+0.4 \mathrm{k}_{\mathrm{S} \omega}$ that is equal to (7) with the deviation calculated by (10).

If the microgrid is operating in grid-connected mode, in steady state, the frequency $\omega$ in Figure 7 is necessarily equal to the system frequency $\omega_{\text {grid }}$. Therefore, if $\omega_{\text {grid }}$ is

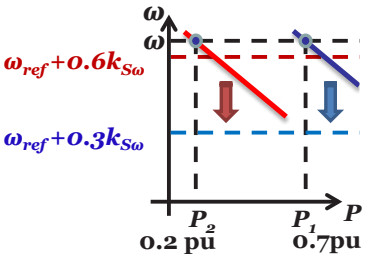

(a)

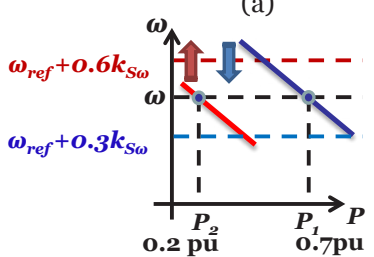

(b)

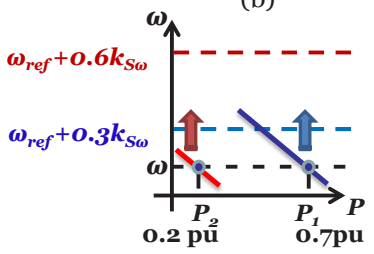

(c)

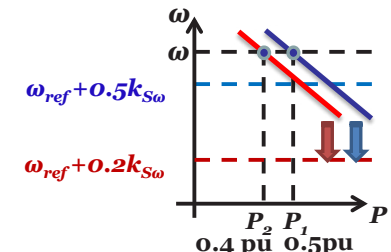

(d)

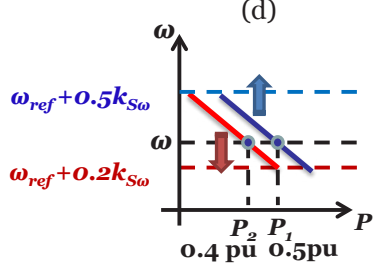

(e)

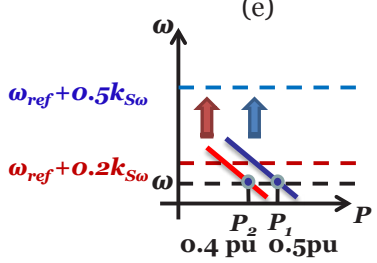

(f)
Fig. 8. Sliding droop control operation in a microgrid with two DG units operating in islanded mode: first scenario with initial frequency deviation a) above, b) between and c) below the frequency range defined by $\delta \omega_{\text {ref }}$, and, second scenario with initial frequency deviation d) above, e) between and f) below the frequency range defined by $\delta \omega_{\text {ref }}$.

regulated and equal to $\omega_{\text {ref }}$, in (7) it results in $\delta \omega_{\text {ref }}=0$ and in (5) this leads to $P=P_{\text {set }}$, that is, the delivered active power is equal to its set point. This ensures that all DG units will dispatch the active power set point in grid-connected mode. Moreover, it allows the grid-operator to indirectly control the DG participation on the active power dispatch by imposing a controlled frequency deviation. This frequency deviation will be exactly the deviation $\delta \omega_{\text {ref }}$, which determines the ratio between the active-power dispatch and the available power $\left(P_{s e t}\right)$. The gain $k_{\omega}$ of the integrator in Figure 7.a, as well as the "sliding limits and protection" block will be explained after the following description of the reactive-power sliding control.

The deviation function for the reactive-power control is

Table I

Sliding Droop Control Operation in a Microgrid with Two DG Units Operating in Islanded Mode

\begin{tabular}{|c|c|c|c|c|c|c|}
\hline DG unit & $\begin{array}{c}\text { Initial sharing } \\
\text { condition }\end{array}$ & $\begin{array}{c}\text { Deviation } \delta \omega_{\text {ref }} \\
\text { eq. (5) } \\
\end{array}$ & Initial frequency condition & $\begin{array}{c}\text { Sliding Direction } \\
\text { eq. (6) } \\
\end{array}$ & $\begin{array}{c}\text { Active Power } \\
\text { change }\end{array}$ & $\begin{array}{c}\text { Microgrid } \\
\text { frequency change }\end{array}$ \\
\hline \multirow{3}{*}{1} & \multirow{3}{*}{0.7} & \multirow{3}{*}{$0.3 k_{S \omega}$} & \multirow{2}{*}{$\omega>\omega_{\text {ref }}+0.6 k_{S \omega}$} & down & no change & \multirow{2}{*}{ decrease } \\
\hline & & & & down & no change & \\
\hline & & & \multirow{2}{*}{$\begin{array}{l}\omega>\omega_{\text {ref }}+0.3 k_{S \omega} \\
\omega<\omega_{\text {ref }}+0.6 k_{S \omega}\end{array}$} & down & decrease & \multirow{2}{*}{ no change } \\
\hline \multirow{3}{*}{2} & \multirow{3}{*}{0.2} & \multirow{3}{*}{$0.6 k_{S \omega}$} & & up & increase & \\
\hline & & & \multirow{2}{*}{$\omega<\omega_{\text {ref }}+0.3 k_{S \omega}$} & up & no change & \multirow{2}{*}{ increase } \\
\hline & & & & up & no change & \\
\hline \multirow{3}{*}{1} & \multirow{3}{*}{0.5} & \multirow{3}{*}{$0.5 k_{S \omega}$} & \multirow{2}{*}{$\omega>\omega_{\text {ref }}+0.5 k_{S \omega}$} & down & no change & \multirow{2}{*}{ decrease } \\
\hline & & & & down & no change & \\
\hline & & & \multirow{2}{*}{$\begin{array}{l}\omega>\omega_{\text {ref }}+0.2 k_{S \omega} \\
\omega<\omega_{\text {ref }}+0.5 k_{S \omega}\end{array}$} & up & increase & \multirow{2}{*}{ no change } \\
\hline \multirow{3}{*}{2} & \multirow{3}{*}{0.4} & \multirow{3}{*}{$0.2 k_{S \omega}$} & & down & decrease & \\
\hline & & & \multirow{2}{*}{$\omega<\omega_{r e f}+0.2 k_{S \omega}$} & up & no change & \multirow{2}{*}{ increase } \\
\hline & & & & up & no change & \\
\hline
\end{tabular}




$$
\delta V_{\text {ref }}=-k_{S V} Q
$$

where $k_{S V}$ is the maximum allowed voltage-amplitude deviation. The gain $k_{S V}$ can be tuned to ensure that negligible voltage deviation is achieved whenever the reactive power of the DG units is enough to regulate the voltage at the bus where it is connected. The sliding direction control block has the same rules as for active power (6) and (7), substituting $\omega$ by $\mathrm{V}$ and with the exception of condition $\left(P>P_{\text {set }}\right)$, which, in case of several DG units connected at a same ac bus, lead respectively to:

$$
\begin{gathered}
\delta V_{r e f_{1}}=\delta V_{r e f_{2}}=\cdots=\delta V_{r e f_{n}} \\
Q_{1}=Q_{2}=\cdots=Q_{n} .
\end{gathered}
$$

Hence, the reactive power sharing is ensured to those DG units. Note that the main differences between the sliding controllers of the active and reactive droop curves are due to the neglecting of the reactive-power reference. However, in future applications, this reference can be considered and simple adaptations of the deviation function and sliding direction rules may enable DG units to perform additional functionalities such as [7].

The integration gains $k_{\omega}$ and $k_{V}$ in Figure 7 are responsible to determine the speeds that the curves slide, and then can be tuned according to typical time responses of hierarchical secondary controllers. Since the possible inputs of these integrators are only -1 or +1 , the integration gains $k_{\omega}$ and $k_{V}$ determine the rate of change of $\delta \omega_{0}$ and $\delta V_{0}$, in $p u / s$, respectively. Note that positive and negative sliding direction oscillations, in steady state, cause negligible disturbances on $\delta \omega_{0}$ and $\delta V_{0}$ due to the large time constants $1 / k_{\omega}$ and $1 / k_{V}$.

The "sliding limits and protection" block avoids undesirable behaviors that can arise during faulty power systems, which can lead the sliding curves to outside the limits. In other words, under abnormal situations, these control blocks prevents the placement of the droop curves in areas that degrade the proper functioning of the DG units. The anti wind-up block interrupts the integration effect whenever the "sliding limits and protection" block acts. The output of the "sliding limits and protection" are the control variables $\omega_{0}$ and $V_{0}$ that feed the droop loops for ensuring the droop effect through $P_{D}$ and $Q_{D}$ power deviations, respectively.

\section{STABILITY}

The satisfactory behavior of the proposed sliding droop control is completely based on the stability of every single controlled DG unit and the grid configuration in which the units operate. Lots of research has been conducted and published for different kind of SSG. Some examples of stability studies are [27] for synchronverters, [28] for current controllers with active damping for LCL grid-connected
VSCs, and [17] for generators in general. For further studies on large configurations of generators and its electrical mechanical stability, many consolidated digital programs can be found. Although they were originally developed for actual generators, SSGs can be adapted to fit in the actual models. This is especially straightforward for the synchronverter.

On top of these stable considered DG units in their grid configuration, connected at main grid or islanding, stands the proposed sliding droop control. This control acts on the secondary level, that is, frequency and voltage control within a predictable margin of error, $k_{S \omega}$ and $k_{S V}$, respectively, see (5) and (11), while power sharing is maintained. As described in the former sections, the functioning of the control is basically sliding the no load references $\omega_{0}$ and $V_{0}$ in up- or down-ward directions, see Figure 5, with fixed speeds, $k_{\omega}$ and $k_{V}$, respectively, as shown in Figure 7.

The choice of the control parameters $k_{S \omega}, k_{S V}, k_{\omega}$ and $k_{V}$ should be in compliance with the grid codes of the area EPS operator where the microgrid is connected at. It seems plausible that the sliding speeds should be comparable with the ones of the grid operator. If the operator decides that the contribution of the renewables is less important as a power source, the gains should be chosen smaller, and vice versa. The same is valid for the error margins. If the operator decides that the participation of renewables should be equal to conventional generators, then the margins should be equal as well.

Whatever value is chosen for these four parameters, in terms of stability, no degradation can be expected for real values of the parameters. Actual values of speed are significantly slow in comparison with primary reactions of the DG units. Further, from a small signal model point of view, $\omega_{0}$ and $V_{0}$ are perturbations, though, never a step input, because of the integrator. Besides this, the "Sliding limits and protection" control block and (6) will always maintain the DG unit in normal operation area. At last the "Anti windup" block attends known instability problems as mentioned in [27].

\section{SIMULATION RESULTS}

Figure 9 illustrates the power system scenario used for simulations. It is a microgrid with multiple DG units controlled as SSGs. For simplicity, all units have the same hardware with an Energy Generator System and dc-link capacitor (see Figure 6), which were replaced by ideal dc sources, since the interest of this work is neither the Energy Management nor the generation system. The DG units \#1 and \#4 have $P_{\text {set }}=1.0 \mathrm{pu}$, and DG units \#2, \#3 and \#5 have $\mathrm{P}_{\text {set }}=0.5 \mathrm{pu}$ during all simulation time. Thus, the total desired (available) power generation in the microgrid is far greater than the total load in the microgrid. In other words, the DG units cannot deliver the desired (total available) active power during isolated mode of operation. The reference values $\omega_{\text {ref }}$ and $V_{\text {ref }}$ are set constant and equal to $1.0 \mathrm{pu}$. Table II shows the parameters of the DG units. The sliding speed of the $Q-V$ curves was tuned much faster than 
Table II

DG Unit Parameters

\begin{tabular}{l|c}
\hline \hline \multicolumn{1}{c|}{ Parameter } & Value \\
\hline $\begin{array}{l}\text { Theoretical installed- } \\
\text { capacity of each DG unit }\end{array}$ & $3.5 \mathrm{kVA}(1 \mathrm{pu})$ \\
\hline Switching frequency & $10260 \mathrm{~Hz}(171 \mathrm{pu})$ \\
\hline & $\mathrm{L}_{\mathrm{c}}=5.21 \mathrm{mH}(0.142 \mathrm{pu})$ \\
Switching filter & $\mathrm{R}_{\mathrm{Lc}}=28 \mathrm{~m} \Omega(0.002 \mathrm{pu})$ \\
(LCL filter) & $\mathrm{C}=4.0 \mu \mathrm{F}(47 \mathrm{pu})$ \\
& $\mathrm{L}_{\mathrm{o}}=2,46 \mathrm{mH}(0.067 \mathrm{pu})$ \\
\hline Time constants $\mathrm{H}$ and $\mathrm{K}$ & $\mathrm{R}_{\mathrm{Lo}}=14 \mathrm{~m} \Omega(0.001 \mathrm{pu})$ \\
\hline$D_{p}$ and $D_{q}$ & $14.4 \mathrm{~s}$ and $16.7 \mathrm{~s}$ \\
\hline$k_{\omega}$ and $k_{V}$ & $200.0 \mathrm{pu}$ and $10.0 \mathrm{pu}$ \\
\hline $\mathrm{k}_{\mathrm{S} \omega}$ and $\mathrm{k}_{\mathrm{SV}}$ & $5 \cdot 10^{-4} \mathrm{pu} / \mathrm{s}$ and $1 \cdot 10^{-2} \mathrm{pu} / \mathrm{s}$ \\
\hline \hline
\end{tabular}

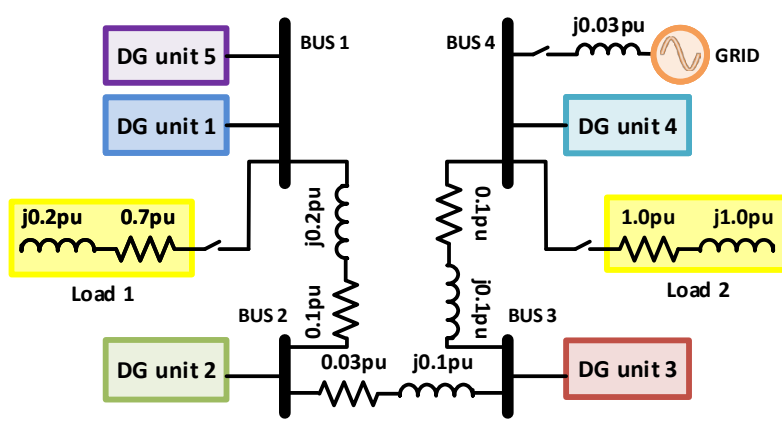

Fig. 9. Microgrid diagram with multiple DG units controlled as SSG.

typical dynamic profile of secondary controllers in order to fit the results in a short simulation time. This was necessary due to constraints in large data storage in the digital simulator. The system events are displayed at the top of Figure 10.

Figure 10 presents the simulation results with the proposed sliding droop control. From the initial condition until $50.0 \mathrm{~s}$, units 1, 2, 3 and 4 are operating with the microgrid in islanded mode and the loads 1 and 2 connected. It is verified that the active power is being shared proportionally to the available active power in each DG unit. This situation is ensured even with the load change, which occurs between $50.0 s$ and $100.0 s$ when load 2 is disconnected. Moreover, the frequency in steady state is kept within the range of $k_{S \omega}$. The DG unit 5 starts at $t=150.0 \mathrm{~s}$. After this time, the system achieves a new operating point and the active power sharing is maintained. Finally, at $t=200.0 \mathrm{~s}$, the microgrid is connected to the grid and then all units dispatch their active-power set points to the grid. The results prove that the proposed sliding droop control enables the DG units to perform the desired goals for active power dispatch in both islanded and grid-connected modes of operation. The reactive power goals are also satisfied. This can be verified through the reactive-power sharing between DG units 1 and 5 , which are connected at the same bus. All DG units provide the reactive-power necessary to keep the voltage amplitudes within the range of $k_{S V}$ in steady state.

For comparisons, the same system was simulated again with the DG units being controlled as SSGs with conventional, fixed droop curves. The slopes of the curves were fixed with the maximum deviation, that is, equal to $k_{S \omega}$ as given in Table II $\left(D_{p}=1 / k_{S \omega}\right)$. Figure 11 shows that

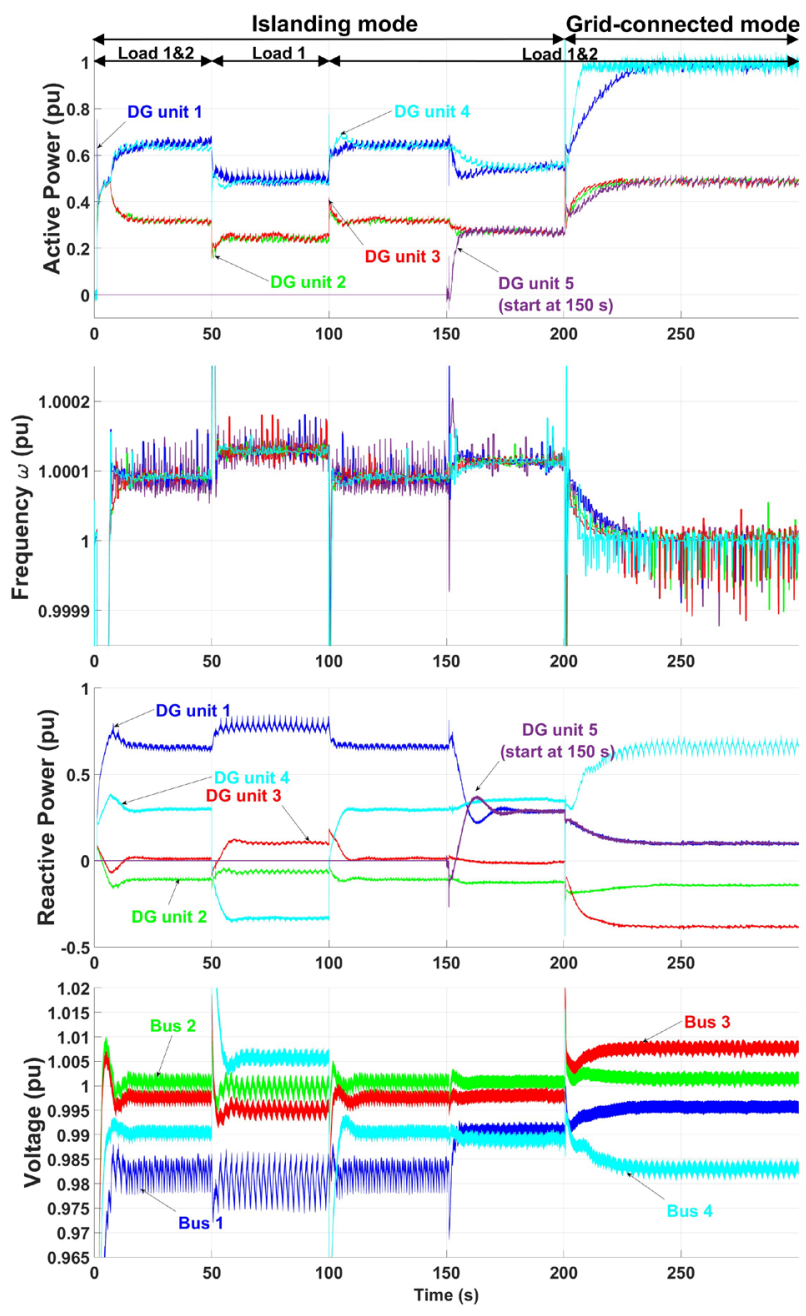

Fig. 10. Simulation results.

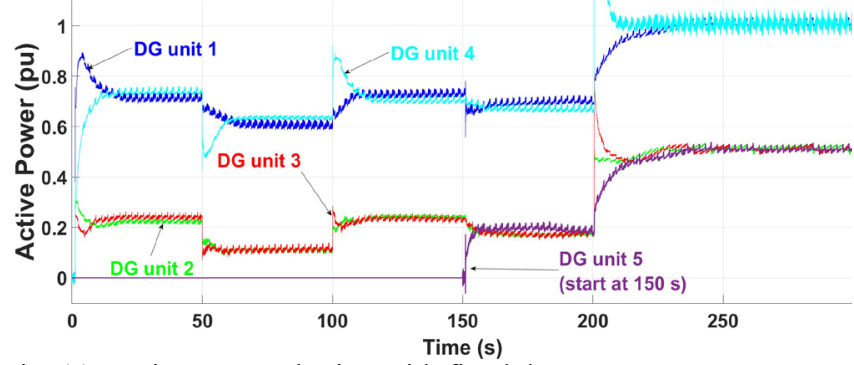

Fig. 11. Active power sharing with fixed droop curves.

units with different active-power set points are not able to perform active-power sharing proportionally to the available power. For instance, between 100 and 150 seconds, DG units \#1 and \#4 dispatch around 0.7 pu while DG units \#2 and \#3 dispatch around $0.25 \mathrm{pu}$. The comparison with the same result shown in Figure 10 makes it clear that the sharing was not performed satisfactorily. In other words, (9) and, consequently, (2), are not satisfied.

\section{EXPERIMENTAL RESULTS}

Two $3.5 \mathrm{kVA}$ prototypes (DG unit 1 and 2) were 
connected to the same bus, as depicted in Figure 12. The switches $\mathrm{S}_{\mathrm{L} 1}, \mathrm{~S}_{\mathrm{L} 2}, \mathrm{~S}_{\mathrm{L} 3}$ and $\mathrm{S}_{\mathrm{L} 4}$ connect load 1, load 2, load 3, and load 4, respectively. The power of the loads is given in $\mathrm{pu}$, according to the power basis of the SSGs. The system is operating in islanded mode in order to evaluate the sharing performance and frequency/voltage regulation. The maximum deviations and sliding speeds were set as $\mathrm{k}_{\mathrm{S} \omega}=$ $1 \cdot 10^{-3} \mathrm{pu}(0.06 \mathrm{~Hz}), \quad \quad \mathrm{k}_{\mathrm{SV}}=2 \cdot 10^{-2} \mathrm{pu}(4.4 \mathrm{~V})$, $k_{\omega}=5 \cdot 10^{-4} \mathrm{pu} / \mathrm{s}$, and $k_{V}=1 \cdot 10^{-3} \mathrm{pu} / \mathrm{s}$. An oscilloscope YOKOGAWA DL850EV was employed to measure simultaneously the voltages and currents of the DG units as well as to calculate the average powers, frequency and voltage amplitude at the bus.

Figure 13 shows the test performed to evaluate the active power sharing and the frequency regulation. In this case, only resistive loads 1 and 2 were employed. Table III presents the system events, which includes startup of DG unit, changes in the available power, $P_{\text {set }}$, and step load change. It is verified that the active power sharing is obtained with reduced error $(4.9 \%$ for the worst case). Moreover, the power sharing is achieved independently of the set point of each unit, as well as independently from the amount of load. Although the frequency calculated by the oscilloscope is hardly affected by the harmonic contents of the synthesized voltages, the mean value (which represents the fundamental frequency) is kept within the maximum deviation stated by $k_{S \omega}$.

Figure 14 shows the test performed to evaluate the reactive power sharing and the voltage regulation. In Figure 14.a, load 1 and load 3 were connected and in Figure 14.b, load 1 and load 4 were connected, both during the entire test. In the initial condition, DG unit 1 is operating in steady state with $P_{\text {set }}=1.0 \mathrm{pu}$ and after 15.0 seconds DG unit 2 starts with $P_{\text {set }}=0.5 \mathrm{pu}$. It is verified that the reactive power sharing was achieved with suitable accuracy, independently of the active power set point and the inductive or capacitive power factor. Moreover, the voltage was kept within the maximum deviation $k_{S V}$ in steady state condition for both power factors.

\section{CONCLUSIONS}

This paper proposes an improvement in the classic control structure of the SSG by adding a sliding droop control at the active and reactive power loops. This provides accurate performance in frequency/voltage regulation and power sharing between units in an islanded microgrid. In a gridconnected configuration, the units are able to inject the desired power orders imposed by $P_{\text {set }}$ and also can operate complementarily as voltage regulators. These functionalities are achieved without the need of a communication channel between the units.

The experimental and simulation results showed suitable performance with multiple unities in different scenarios. The transition between islanded and grid-connected modes was successfully achieved, as well as step changes in power order $P_{\text {set }}$ and relatively large load rejection and reclosing. These hard tests demonstrated the large stability margin of the proposed control method as a solution for DG units in Distributed Power Systems.

Future works will contain more profound stability studies, operational performance and transitory condition of islanded microgrids with different values of the maximum allowed frequency/voltage deviation in steady state and sliding speeds of the droop curves. These studies are necessary to

Table III System Events (Figure 13)

\begin{tabular}{l|c}
\hline \hline \multicolumn{1}{c|}{ Event } & Time \\
\hline Load 1 connected and Load 2 disconnected & Initial condition \\
\hline DG unit 2 in steady state with $P_{\text {set }}=1.0 \mathrm{pu}$ & Initial condition \\
\hline DG unit 1 startup with $P_{\text {set }}=0.5 \mathrm{pu}$ & $20.0 \mathrm{~s}$ \\
\hline DG unit 1 set point change to $P_{\text {set }}=1.0 \mathrm{pu}$ & $60.0 \mathrm{~s}$ \\
\hline DG unit 2 set point change to $P_{\text {set }}=0.5 \mathrm{pu}$ & $100.0 \mathrm{~s}$ \\
\hline DG unit 2 set point change to $P_{\text {set }}=1.0 \mathrm{pu}$ & $140.0 \mathrm{~s}$ \\
\hline Load 2 connection & $160.0 \mathrm{~s}$ \\
\hline \hline
\end{tabular}

Fig. 12. Experimental bench.
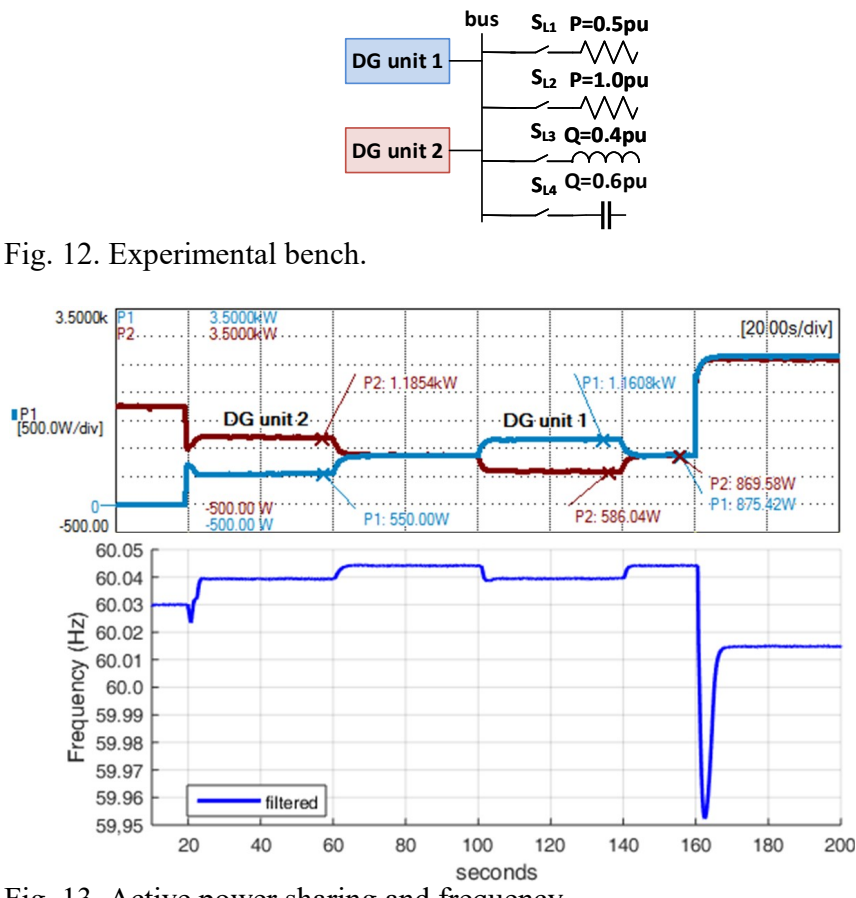

Fig. 13. Active power sharing and frequency.
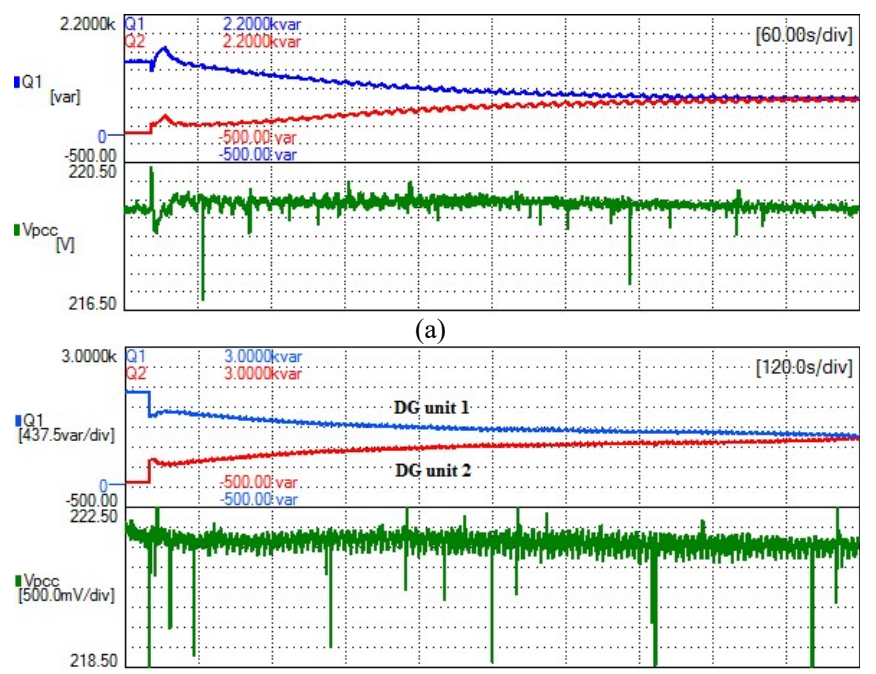

(b)

Fig. 14. Reactive power sharing and voltage amplitude: a) Inductive power factor with loads 1 and 3, b) Capacitive power factor with loads 1 and 4 . 
achieve suitable performance of DG units with ensured stable conditions, reduced frequency/voltage deviation and suitable fast response.

\section{REFERENCES}

[1] J. M. Guerrero, "Connecting renewable energy sources into the smartgrid," in IEEE International Symposium on Industrial Electronics (ISIE), pp. 2400-2566, 2011.

[2] F. Blaabjerg, R. Teodorescu, M. Liserre, A. V. Timbus, "Overview of Control and Grid Synchronization for Distributed Power Generation Systems," IEEE Transactions on Industrial Electronics, vol. 53, no. 5, pp. 1398-1409, October 2006.

[3] J. M. Carrasco, L. G. Franquelo, J. T. Bialasiewicz, E. Galván, R. C. P. Guisado, M. A. M. Prats, J. I. León, N. Moreno-Alfonso, "Power-Electronic Systems for the Grid Integration of Renewable Energy Sources: A Survey," IEEE Transactions on Industrial Electronics, vol. 53, no. 4, pp. 1002-1016, August 2006.

[4] Q.-C. Zhong, G. Weiss, "Static synchronous generators for distributed generation and renewable energy," in IEEE/PES Power Systems Conference and Exposition, PSCE, pp. 1-6, 2009.

[5] Q.-C. Zhong, G. Weiss, "Synchronverters: Inverters That Mimic Synchronous Generators," IEEE Transactions on Industrial Electronics, vol. 58, no. 4, pp. 1259-1267, April 2011

[6] Z. Ma, Q.-C. Zhong, J. D. Yan, "Synchronverter-based control strategies for three-phase PWM rectifiers," in 7th IEEE Conference on Industrial Electronics and Applications (ICIEA), pp. 225-230, 2012.

[7] P.-L. Nguyen, Q.-C. Zhong, F. Blaabjerg, J. M. Guerrero, "Synchronverter-based operation of STATCOM to Mimic Synchronous Condensers," in 7th IEEE Conference on Industrial Electronics and Applications (ICIEA), pp. 942-947, 2012.

[8] P. Rodriguez, I. Candela, A. Luna, "Control of PV generation systems using the synchronous power controller," in IEEE Energy Conversion Congress and Exposition (ECCE), pp. 993-998, 2013.

[9] Q.-C. Zhong, "Power-Electronics-Enabled Autonomous Power Systems: Architecture and Technical Routes," IEEE Transactions on Industrial Electronics, vol. 64, no. 7, pp. 5907-5918, July 2017.

[10] J. C. Vasquez, J. M. Guerrero, A. Luna, P. Rodriguez, R. Teodorescu, "Adaptive Droop Control Applied to Voltage-Source Inverters Operating in Grid-Connected and Islanded Modes," IEEE Transactions on Industrial Electronics, vol. 56, no. 10, pp. 4088-4096, October 2009.

[11] A. Mondal, M. S. Illindala, A. S. Khalsa, D. A. Klapp, J. H. Eto, "Design and Operation of Smart Loads to Prevent Stalling in a Microgrid," IEEE Transactions on Industry Applications, vol. 52, no. 2, pp. 1184-1192, March-April 2016.

[12] Y. Han, H. Li, L. Xu, X. Zhao, J. Guerrero, "Analysis of Washout Filter-Based Power Sharing Strategy-An
Equivalent Secondary Controller For Islanded Microgrid without LBC Lines," IEEE Transactions on Smart Grid, vol. PP, pp. 1-1, 2017.

[13] J. W. Simpson-Porco, Q. Shafiee, F. Dörfler, J. C. Vasquez, J. M. Guerrero, F. Bullo, "Secondary Frequency and Voltage Control of Islanded Microgrids via Distributed Averaging," IEEE Transactions on Industrial Electronics, vol. 62, no.11, pp. 7025-7038, Nov. 2015.

[14] J. M. Guerrero, J. C. Vasquez, J. Matas, M. Castilla, L. G. de Vicuna, "Control Strategy for Flexible Microgrid Based on Parallel Line-Interactive UPS Systems," IEEE Transactions on Industrial Electronics, vol. 56, no. 3, pp. 726-736, March 2009.

[15] C.-T. Lee, C.-C. Chu, P.-T. Cheng, "A new droop control method for the autonomous operation of distributed energy resource interface converters," in IEEE Energy Conversion Congress and Exposition (ECCE), pp. 702-709, 2010.

[16] H. Han, Y. Liu, Y. Sun, M. Su, J. M. Guerrero, "An Improved Droop Control Strategy for Reactive Power Sharing in Islanded Microgrid," IEEE Transactions on Power Electronics, vol. 30, no. 6, pp. 3133-3141, June 2015.

[17] P. Kundur, Power System Stability and Control, McGraw-Hill Professional, 1994.

[18] S. Chapman, Electric Machinery Fundamentals, 5th ed., New York: McGraw-Hill Science/Engineering/Math, 2011.

[19] J. M. Guerrero, M. Chandorkar, T. L. Lee, P. C. Loh, "Advanced Control Architectures for Intelligent Microgrids-Part I: Decentralized and Hierarchical Control," IEEE Transactions on Industrial Electronics, vol. 60, no.4, pp. 1254-1262, April 2013.

[20] J. Driesen, K. Visscher, "Virtual synchronous generators," in IEEE Power and Energy Society General Meeting - Conversion and Delivery of Electrical Energy in the 21st Century, pp. 1-3, 2008.

[21] F. Gao, M. R. Iravani, "A Control Strategy for a Distributed Generation Unit in Grid-Connected and Autonomous Modes of Operation," IEEE Transactions on Power Delivery, vol. 23, no. 2, pp. 850-859, April 2008.

[22] M. Karimi-Ghartemani, S. A. Khajehoddin, P. Piya, M. Ebrahimi, "Universal Controller for Three-Phase Inverters in a Microgrid," IEEE Journal of Emerging and Selected Topics in Power Electronics, vol. 4, no. 4, pp. 1342-1353, Dec. 2016.

[23] Q.-C. Zhong, "Robust Droop Controller for Accurate Proportional Load Sharing Among Inverters Operated in Parallel," IEEE Transactions on Industrial Electronics, vol. 60, no. 4, pp. 1281-1290, April 2013.

[24] IEEE Application Guide for IEEE Std 1547(TM), IEEE Standard for Interconnecting Distributed Resources with Electric Power Systems, IEEE Std 1547.2-2008, pp. 1-217, April 2009.

[25] IEEE Standard for Interconnecting Distributed 
Resources with Electric Power Systems - Amendment 1, IEEE Std 1547a-2014 (Amendment to IEEE Std 15472003), pp. 1-16, May 2014.

[26] E. Robles, J. Pou, S. Ceballos, J. Zaragoza, J. L. Martín, P. Ibañez, "Frequency-Adaptive Stationary-ReferenceFrame Grid Voltage Sequence Detector for Distributed Generation Systems," IEEE Transactions on Industrial Electronics, vol. 58, no. 9, pp. 4275-4287, Sep. 2011.

[27] Q.-C. Zhong, G. C. Konstantopoulos, B. Ren, M. Krstic, "Improved Synchronverters with Bounded Frequency and Voltage for Smart Grid Integration," IEEE Transactions on Smart Grid, vol. PP, no. 99, pp. 1-1, 2016.

[28] E. Rodriguez-Diaz, F. D. Freijedo, M. S. Golsorkhi, J. C. Vasquez, J. M. Guerrero, "A root-locus design methodology derived from the impedance stability criterion and its application for LCL grid-connected converters," in 18th European Conference on Power Electronics and Applications (EPE ECCE Europe), pp. 1-10, 2016.

\section{BIOGRAPHIES}

Bruno W. Franca, born in $05 / 27 / 1986$ in Rio de Janeiro, Brazil, is an electrical engineer (2009 Cum Laude), master (2012) and doctor in Electrical Engineering (2016) with the Federal University of Rio de Janeiro, COPPE/UFRJ. He is currently an Adjunct Professor I at Fluminense Federal University. His areas of interest are: power electronics, distributed generation, power quality, renewable energy, FACTS and active filters. Dr. França is member of the SOBRAEP and IEEE.
Emanuel L. van Emmerik, born in 10/25/1968 in Leiden, the Netherlands, is an electrical engineer and master (1991 Cum Laude) in Electrical Engineering with the Technical University of Delft. Since 2002 he is a researcher of Laboratory LEMT, COPPE/UFRJ where he started his D.Sc. in Electrical Engineering in 2013. His areas of interest are microgrids, distributed generation, FACTS, power systems and drives. Emanuel is member of the SOBRAEP.

Juliano F. Caldeira, born in 11/12/1978 in Rio de Janeiro, Brazil, is an electronic engineer (2008) and master in Electrical Engineering (2012) with the Federal University of Rio de Janeiro, COPPE/UFRJ. In 2013 he started his D.Sc. in Electrical Engineering at COPPE/UFRJ. His areas of interest are smart energy metering, NILM, microgrids, energy efficiency and machine learning.

Mauricio Aredes, born in 14/08/1961 in São Paulo, Brazil, is an electrical engineer (1984) with the Fluminense Federal University, master (1991) with the Federal University of Rio de Janeiro and doctor in Electrical Engineering. (1996 Hons.) with the Technische Universitat Berlim. Currently, he is an Associate Professor at the Federal University of Rio de Janeiro, where he lectures Power Electronics. From 1985 to 1997, he was P\&D-Engineer at the Research Center of Electric Energy (CEPEL), Rio de Janeiro. His research areas include HVDC systems, FACTS, active filters, custom power and power quality. Dr. Aredes is member of the SOBRAEP and senior member of IEEE. 